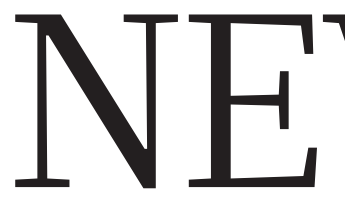

TEch Excitement and concern as AI migrates to industry $\mathbf{p . 4 2 2}$
HEALTH Cancer 'moonshots' are lacking joined-up thinking $\mathbf{p . 4 2 4}$
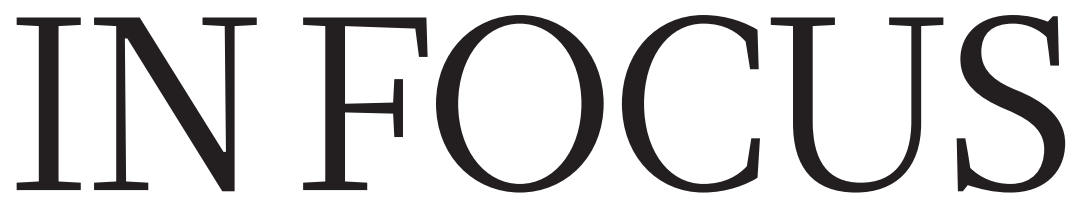

PHrsics Europe quietly plans a quantum revolution $\mathbf{p . 4 2 6}$

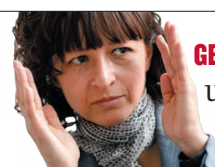

GENE EDITING How CRISPR

upended Emmanuelle Charpentier's life $\mathbf{p . 4 2 8}$

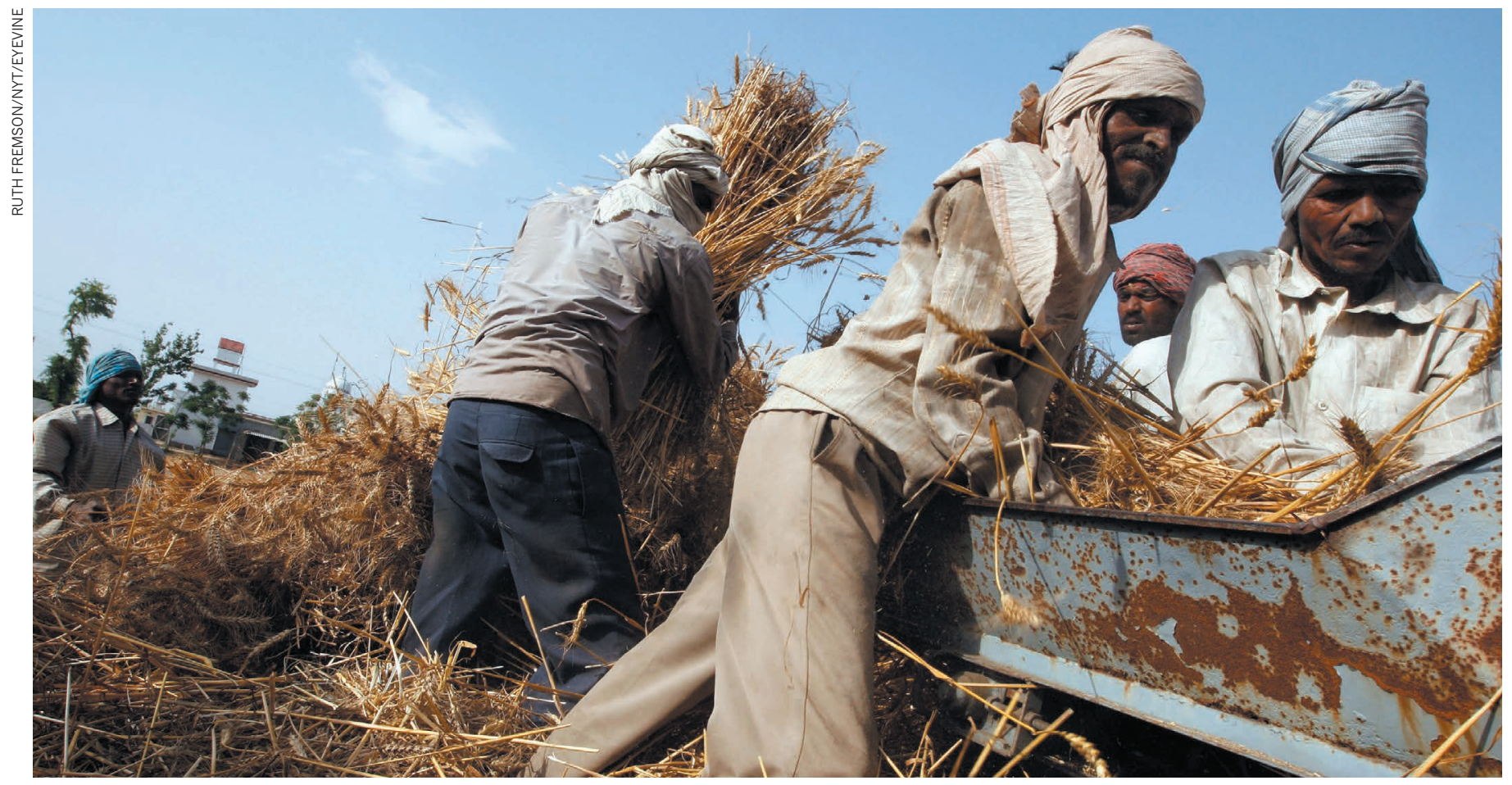

Wheat in northern India could be threatened by an outbreak of fungal disease in Bangladesh.

\title{
Devastating wheat fungus appears in Asia for first time
}

\section{No one knows the origin of the Bangladesh outbreak, which scientists warn could spread.}

\section{BY EWEN CALLAWAY}

$\mathrm{F}$ Tields are ablaze in Bangladesh, as farmers struggle to contain Asia's first outbreak of a fungal disease that periodically devastates crops in South America. Plant pathologists warn that wheat blast could spread to other parts of south and southeast Asia, and are hurrying to trace its origins.

"It's important to know what the strain is," says Sophien Kamoun, a biologist at the Sainsbury Laboratory in Norwich, UK, who has created a website, Open Wheat Blast (go.nature.com/ bkczwf), to encourage researchers to share data.
Efforts are also under way to find wheat genes that confer resistance to the disease.

First detected in February and confirmed with genome sequencing by Kamoun's lab this month, the wheat-blast outbreak has already caused the loss of more than 15,000 hectares of crops in Bangladesh. "It's really an explosive, devastating disease," says plant pathologist Barbara Valent of Kansas State University in Manhattan, Kansas. "It's really critical that it be controlled in Bangladesh."

After rice, wheat is the second most cultivated grain in Bangladesh, which has a population of 156 million people. More broadly, inhabitants of south Asia grow 135 million tonnes of wheat each year.

Wheat blast is caused by the fungus Magnaporthe oryzae. Since 1985, when scientists discovered it in Brazil's Paraná state, the disease has raced across South America.

The fungus is better known as a pathogen of rice. But unlike in rice, where $M$. oryzae attacks the leaves, the fungus strikes the heads of wheat, which are difficult for fungicides to reach. A 2009 outbreak in wheat cost Brazil one-third of that year's crop. "There are regions in South America where they don't grow wheat because of the disease," Valent says. Wheat blast was 
- spotted in Kentucky in 2011, but vigorous surveillance helped to stop it spreading in the United States.

In South America, the disease tends to take hold in hot and humid spells. Such conditions are present in Bangladesh, and the disease could migrate across south and southeast Asia, say plant pathologists. In particular, it could spread over the Indo-Gangetic Plain through Bangladesh, northern India and eastern Pakistan, warn scientists at the Bangladesh Agricultural Research Institute (BARI) in Nashipur.

Bangladeshi officials are burning government-owned wheat fields to contain the fungus, and telling farmers not to sow seeds from infected plots. The BARI hopes to identify wheat varieties that are more tolerant of the fungus and agricultural practices that can keep it at bay, such as crop rotation and seed treatment.

It is unknown how wheat blast got to Bangladesh. One possibility is that a wheat-infecting strain was brought in from South America, says Nick Talbot, a plant pathologist at the University of Exeter, UK. Another is that an M. oryzae strain that infects south Asian grasses somehow jumped to wheat, perhaps triggered by an environmental shift: that is what happened in Kentucky, when a rye-grass strain infected wheat.

To tackle the question, this month Kamoun's lab sequenced a fungus sample from Bangladesh. The strain seems to be related to those that infect wheat in South America, says Kamoun, but data from other wheat-infecting strains and strains that plague other grasses are needed to pinpoint the outbreak's origins conclusively.

The Open Wheat Blast website might help. Kamoun has uploaded the Bangladeshi data, and Talbot has deposited M. oryzae sequences from wheat in Brazil. Talbot hopes that widely accessible genome data could help to combat the outbreak. Researchers could use them to screen seeds for infection or identify wild grasses that can transmit the fungus to wheat fields.

Rapid data sharing is becoming more common in health emergencies, such as the outbreak of Zika virus in the Americas. Kamoun and Talbot say that their field should follow suit. "The plant-pathology community has a responsibility to allow data to be used to combat diseases that are happening now, and not worry too much about whether they may or may not get a Nature paper out of it," says Talbot.

Last month, Valent's team reported the first gene variant known to confer wheat-blast resistance (C. D. Cruz et al. Crop Sci. http://doi.org/ bfk7; 2016), and field trials of crops that bear the resistance gene variant have begun in South America. But plant pathologists say that finding one variant is not enough: wheat strains must be bred with multiple genes for resistance, to stop M. oryzae quickly overcoming their defences.

The work could help in the Asian crisis, says Talbot. "What I would hope for out of this sorry situation," he says, "is that there will be a bigger international effort to identify resistance genes." -

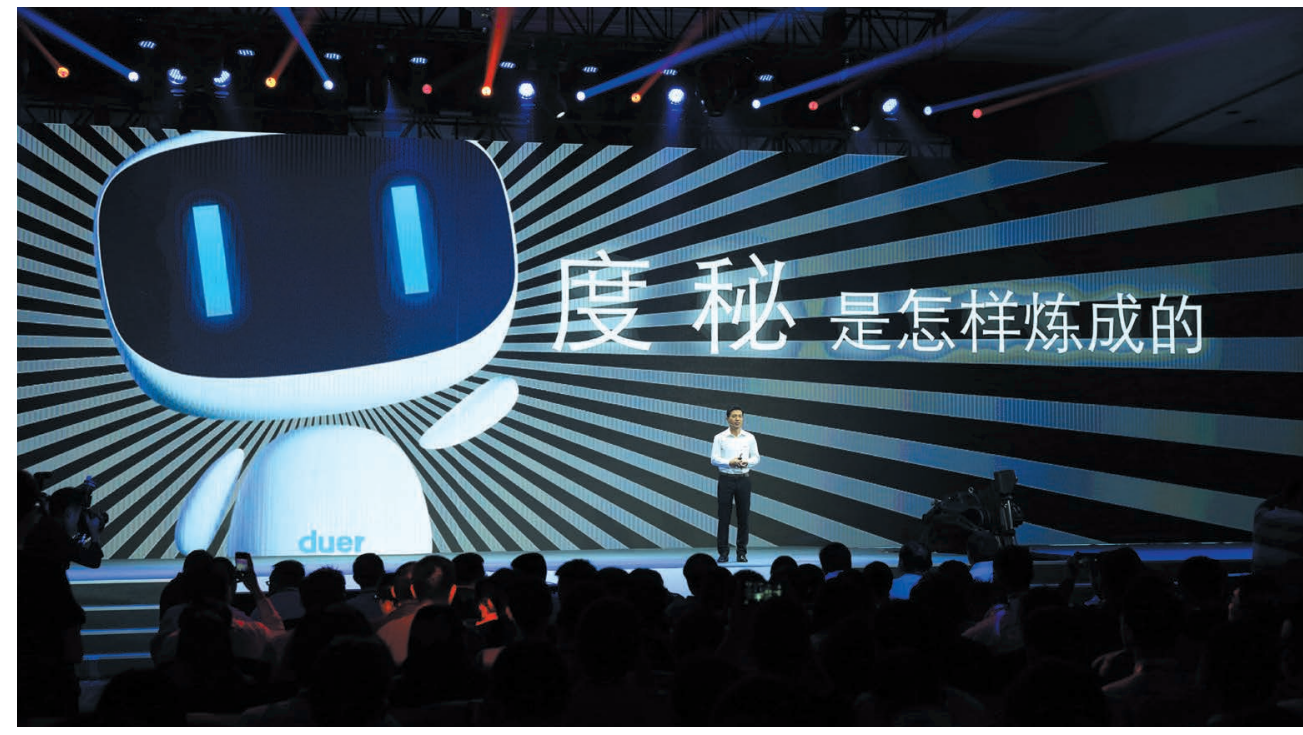

Robin Li, head of China's web giant Baidu, unveils the firm's intelligent digital assistant, Duer.

ARTIFICIAL INTELLIGENCE

\section{AI firms lure academics}

\section{Shift to industry sparks excitement - and some concern.}

\section{BY ELIZABETH GIBNEY}

$\mathrm{W}$ hen Andrew Ng joined Google from Stanford University in 2011, he was among a trickle of artificial-intelligence (AI) experts in academia taking up roles in industry.

Five years later, demand for expertise in AI is booming - and a torrent of researchers is following Ng's lead. The laboratories of tech titans Google, Microsoft, Facebook, IBM and Baidu (China's web-services giant) are stuffed with ex-university scientists, drawn to private firms' superior computing resources and salaries. "Some people in academia blame me for starting part of this," says Ng, who in 2014 moved again to become chief scientist at Baidu, working at the company's research lab in California's Silicon Valley.

Many scientists say that the intense corporate interest is a boon to $\mathrm{AI}$ - bringing vast engineering resources to the field, demonstrating its real-world relevance and attracting eager students. But some are concerned about the more subtle impacts of the industrial migration, which leaves universities temporarily devoid of top talent, and could ultimately sway the field towards commercial endeavours at the expense of fundamental research.
Private firms are investing heavily in $\mathrm{AI}$ - and in particular in an AI technique called deep learning - because of its promise to glean understanding from huge amounts of data. Sophisticated AI systems might be able to create effective digital personal assistants, control self-driving cars, or take on a host of other tasks that are too complex for conventional programming. And corporate labs' resources allow progress that might not be possible in academic departments, says Geoffrey Hinton, a deep-learning pioneer at the University of Toronto in Canada who took up a post at Google in 2013. The fields of speech and image recognition, for instance, had been held up for years by a lack of data to use in training algorithms and a shortage of hardware, he says - bottlenecks that he was able to get past at Google.

"AI is so hot right now. There are so many opportunities and so few people to work on them," says $\mathrm{Ng}$, who says he was attracted by Google's reams of data and computing power, and its ability to tackle real-world problems. Another temptation is that private firms can offer "astronomical" wages, says Tara Sinclair, chief economist at Indeed, a firm headquartered in Austin, Texas, that aggregates online job listings and has chronicled a rising demand for jobs in AI in Britain and the United States.

The excitement shows that $\mathrm{AI}$ is at a point at 